\title{
50 years Mineralium Deposita
}

\author{
Bernd Lehmann • Georges Beaudoin
}

Received: 29 December 2014 / Accepted: 30 December 2014 / Published online: 18 January 2015

(C) Springer-Verlag Berlin Heidelberg 2015

The first issue of Mineralium Deposita came out in May 1966 and had 75 pages (Fig. 1), with a total of 260 pages for the three issues of this first volume. Paul Ramdohr, the then Honorary President of the Society for Geology Applied to Mineral Deposits (SGA), defined the baseline of the journal in the Preface: Focus on new field and laboratory observations, and as little theory and opinion as possible; no repetition and doctrine, and concise style. These aspirations remain valid today. Mineralium Deposita initially published research in English, German, and French until the early 1990s, with bilingual abstracts; the journal since publishes papers in English, following the global trend in scientific literature.

Mineralium Deposita was run for the first 25 years in the traditional way of a scholarly European journal, under the successive editorships of G. Christian Amstutz (Heidelberg), Albert Maucher (München), and Dietrich D. Klemm (München) together with Hans-Jochen Schneider (Berlin). Change came with the somewhat turbulent 2-year troika of editors D.D. Klemm-I. Plimer-D. Rickard in the early 1990s, which ended by the establishment of a professional editorial office in Cardiff, UK, under the leadership of David Rickard, assisted by the unforgotten Vera Walters. This was the time when an independent review system was firmly established, and also when computerized systems started to

B. Lehmann $(\bowtie)$

Technical University of Clausthal,

38678 Clausthal-Zellerfeld, Germany

e-mail: lehmann@min.tu-clausthal.de

G. Beaudoin

Université Laval, Québec, Qc. G1V 0A6, Canada

e-mail: beaudoin@ggl.ulaval.ca be introduced by Springer. The journal matured and became international in scope with the appointment of co-editor Richard Goldfarb in Denver, USA, in 1997. Since then, Mineralium Deposita has had two editorial offices, one in Europe, and one abroad. The US editorial office was taken over by Larry D. Meinert in 2003 (Pullman and Northampton), and then transferred to Townsville, Australia, with Patrick

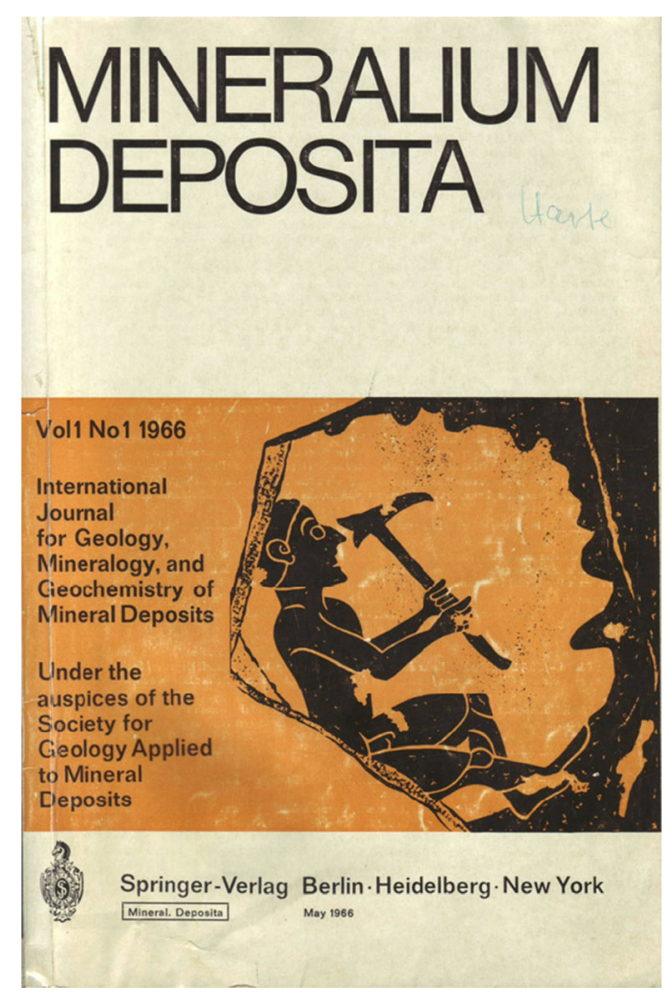

Fig. 1 The cover of the first issue of Mineralium Deposita 
Fig. 2 The editors of Mineralium Deposita over the last 50 years

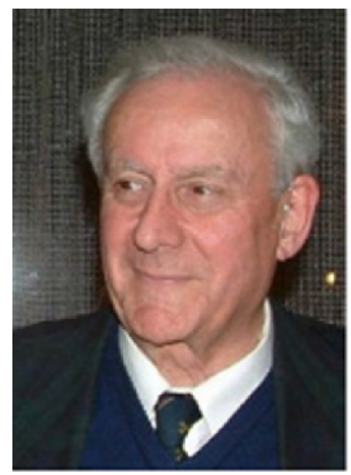

G.C. Amstutz 1966 - 1971

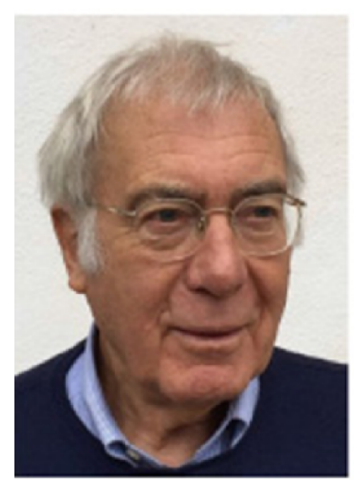

D.D. Klemm 1980 - 1992

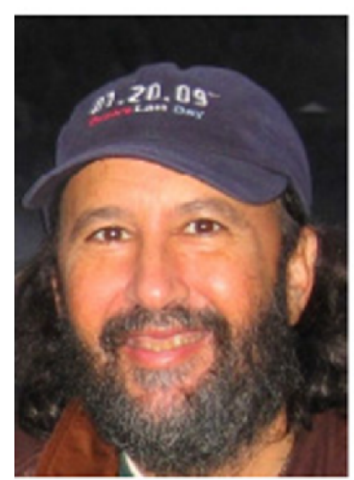

R. Goldfarb $1997-2002$

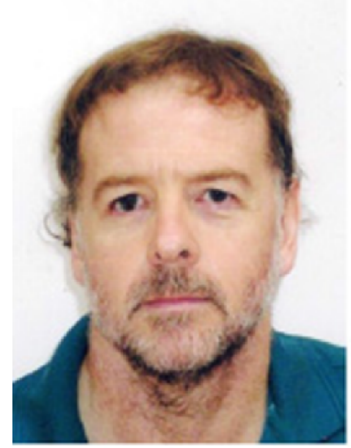

P. Williams $2008-2012$

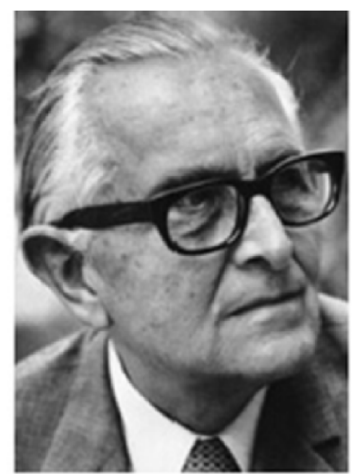

A. Maucher $1972-1979$

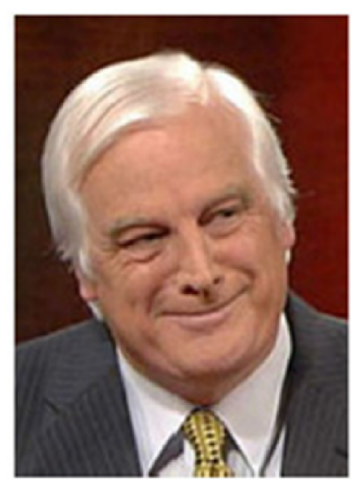

I. Plimer 1991 - 1992

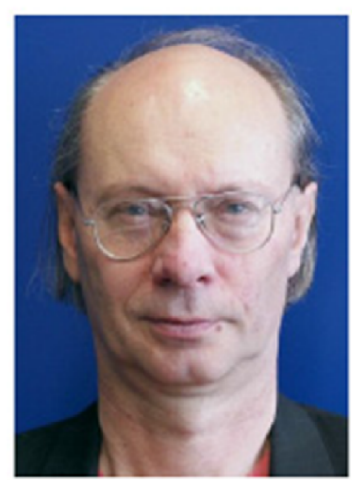

B. Lehmann 2000 - present

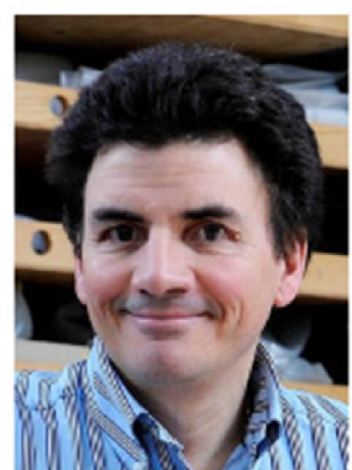

G. Beaudoin 2012 - present

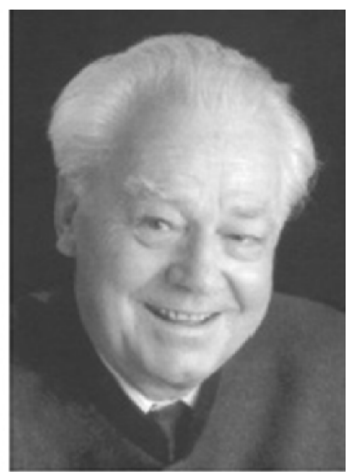

H.-J. Schneider 1980 - 1990

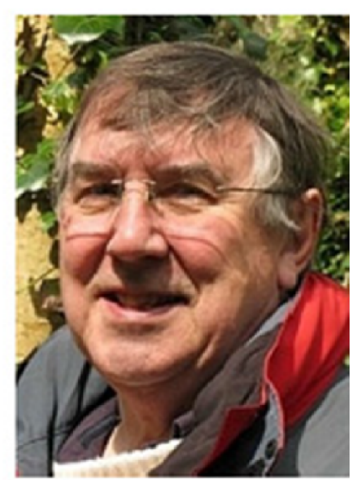

D. Rickard 1991 - 1999

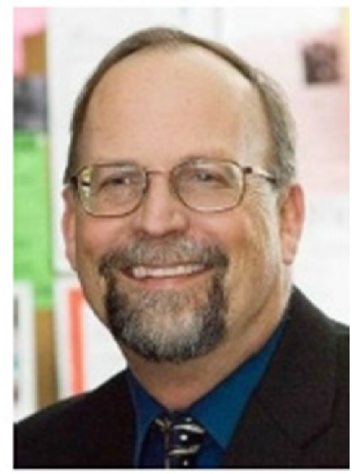

L.D. Meinert $2003-2008$ 


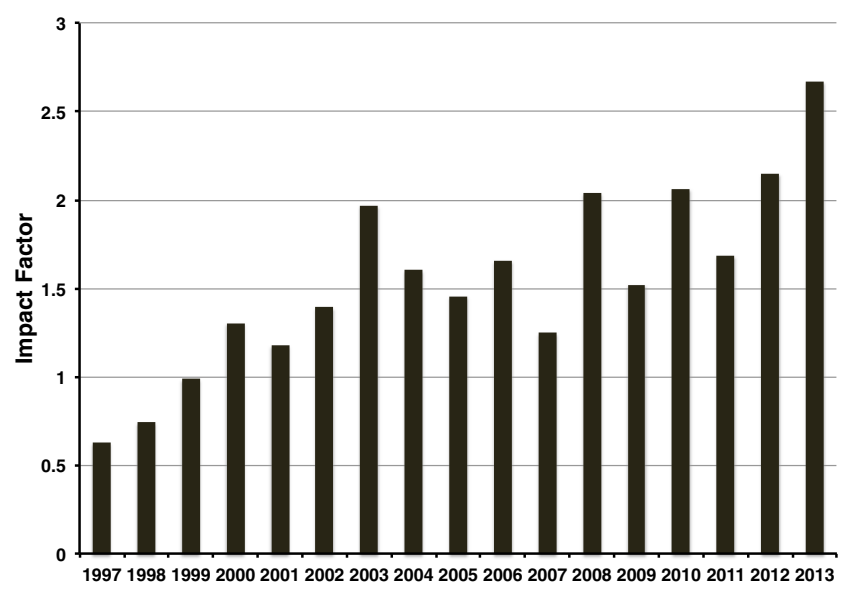

Fig. 3 The Thomson-Reuters Impact Factor of Mineralium Deposita since 1997

Williams in 2008. This office moved on to Quebec City, Canada, with the appointment of Georges Beaudoin in 2012. In 2000, the European office was transferred to Clausthal, Germany, when Bernd Lehmann was appointed co-editor. Figure 2 shows the editors of Mineralium Deposita. By all measures, Mineralium Deposita is now one of the leading scientific journals on mineral deposit geology. An example is provided by the journal's impact factor (IF), which is the ratio of citations in 1 year on the number of papers published over the past 2 years. As shown below in Fig. 3, the IF of Mineralium Deposita has grown continuously since 1997, with the onset of bibliometric data, attesting to the scientific impact of the journal's content.

The editors are only a small part of the journal. We critically depend on the expertise of the members of the editorial board, currently composed of 20 associate editors, who handle the review process for most of the submissions. The efficiency of the peer-review system is much dependent on the many dedicated referees around the world that provide critical reviews to ensure the scientific merit of accepted contributions. The real merit and reputation of the journal rests, of course, on the scientific quality of the contributions we receive, which are a direct reflection of the excellence of the research carried out by the authors that choose Mineralium Deposita for publication of their work.

Another very important ingredient of the journal's success is the technical and commercial know-how of the publisher. We were lucky to have the late Wolfgang Engel as mentor and brilliant Geoscience editor with
Springer from 1984 to 2006 who helped much in the transformation of Mineralium Deposita into a modern science journal. The journal has since benefited from the support of Springer's Geoscience editors Chris Bendall and Annett Buettner. We thank very much the current production teams in Metro Manila, Philippines, and Heidelberg, Germany, for their dedicated daily work to keep the high standards of technical quality. Today, Mineralium Deposita offers colour figures free of charge to all authors, and the journal is printed on high quality paper that makes it stand out. The electronic version of the papers is published at high resolution in PDF format that are accessible at the journal's website at http://link. springer.com/journal/126.

The 50 years of Mineralium Deposita have seen tremendous changes in the manner scientific publications are delivered. The peer review has gone from expediting, by air mail, copies of the submissions to referees across the world to an electronic system archiving the details of the review process, paperless. The typesetting has evolved from manual operations to automatized print on demand of journal copies. The record of the journal has changed from paper to the electronic digital object identifier (DOI). There are numerous advantages to this transition, for authors the most obvious is that a paper is published and citable as soon as the typesetting has been completed. These have been accompanied by a change in the distribution model of the publisher, and by change in the manner scientific libraries purchase rights to access the content of Mineralium Deposita. Hardcopy subscriptions are decreasing but, in exchange, electronic subscriptions are increasing, and Mineralium Deposita is accessible in close to 9000 libraries worldwide. This wide distribution ensures that papers in Mineralium Deposita are accessible to numerous researchers and practitioners, and that the cutting-edge knowledge published in the journal is widely available.

What to expect for the next 50 years? Certainly, the near future will see completion of the transition to electronic delivery of scientific content. The field of mineral deposit geology will remain a vibrant scientific endeavour as the global need for mineral resources keeps increasing. This is driving innovation for understanding the formation of mineral deposits and the methods to find them in new places and at greater depths. Mineralium Deposita will remain at the forefront of these exciting scientific developments. 